\title{
Effects of stretching exercises on human gait: a systematic
}

\section{review and meta-analysis [version 1; peer review: 2 approved}

\section{with reservations]}

\author{
Thomas Vialleron (iD1,2, Arnaud Delafontaine (D1) 1,2, Sebastien Ditcharles 1-3, \\ Paul Fourcade ${ }^{1,2}$, Eric Yiou ${ }^{1,2}$ \\ ${ }^{1}$ CIAMS, Univ. Paris-Sud., Université Paris-Saclay, Orsay, 91405, France \\ ${ }^{2}$ CIAMS, Université d'Orléans, Orléans, Orléans, 45067, France \\ ${ }^{3}$ ENKRE, Saint Maurice, Ile de France, 94410, France
}

V1 First published: 13 Aug 2020, 9:984

https://doi.org/10.12688/f1000research.25570.1

Latest published: 30 Oct 2020, 9:984

https://doi.org/10.12688/f1000research.25570.2

\section{Abstract}

Background: Stretching is commonly used in physical therapy as a rehabilitation tool to improve range of motion and motor function. However, is stretching an efficient method to improve gait, and if so, for which patient category?

Methods: A systematic review of randomized and non-randomized controlled trials with meta-analysis was conducted using relevant databases. Every patient category and every type of stretching programs were included without multicomponent programs. Data were meta-analysed where possible. Estimates of effect sizes (reported as standard mean difference (SMD)) with their respective $95 \%$ confidence interval $(95 \% \mathrm{CI}$ ) were reported for each outcome. The PEDro scale was used for the quality assessment.

Results: Twelve studies were included in the analysis. Stretching improved gait performance as assessed by walking speed and stride length only in a study with a frail elderly population, with small effect sizes (both SMD $=0.49 ; 95 \%$ CI: 0.03, 0.96; PEDro score: $3 / 10$ ). The total distance and the continuous walking distance of the six-minute walking test were also improved only in a study in an elderly population who had symptomatic peripheral artery disease, with large effect sizes (SMD $=1.56 ; 95 \% \mathrm{CI}: 0.66,2.45$ and $\mathrm{SMD}=3.05 ; 95 \% \mathrm{CI}$ : $1.86,4.23$, respectively; PEDro score: 5/10). The results were conflicting in healthy older adults or no benefit was found for most of the performance, spatiotemporal, kinetic and angular related variables. Only one study (PEDro score: 6/10) showed improvements in stance phase duration ( $\mathrm{SMD}=-1.92 ; 95 \% \mathrm{CI}:-3.04,-0.81$ ), swing phase duration ( $\mathrm{SMD}=1.92 ; 95 \mathrm{CI}: 0.81,3.04)$, double support phase duration ( $\mathrm{SMD}=-1.69 ; 95 \% \mathrm{CI}:-2.76,-0.62)$ and step length (SMD=1.37; $95 \%$ CI: $0.36,2.38$ ) with large effect sizes.

Conclusions: There is no strong evidence supporting the beneficial

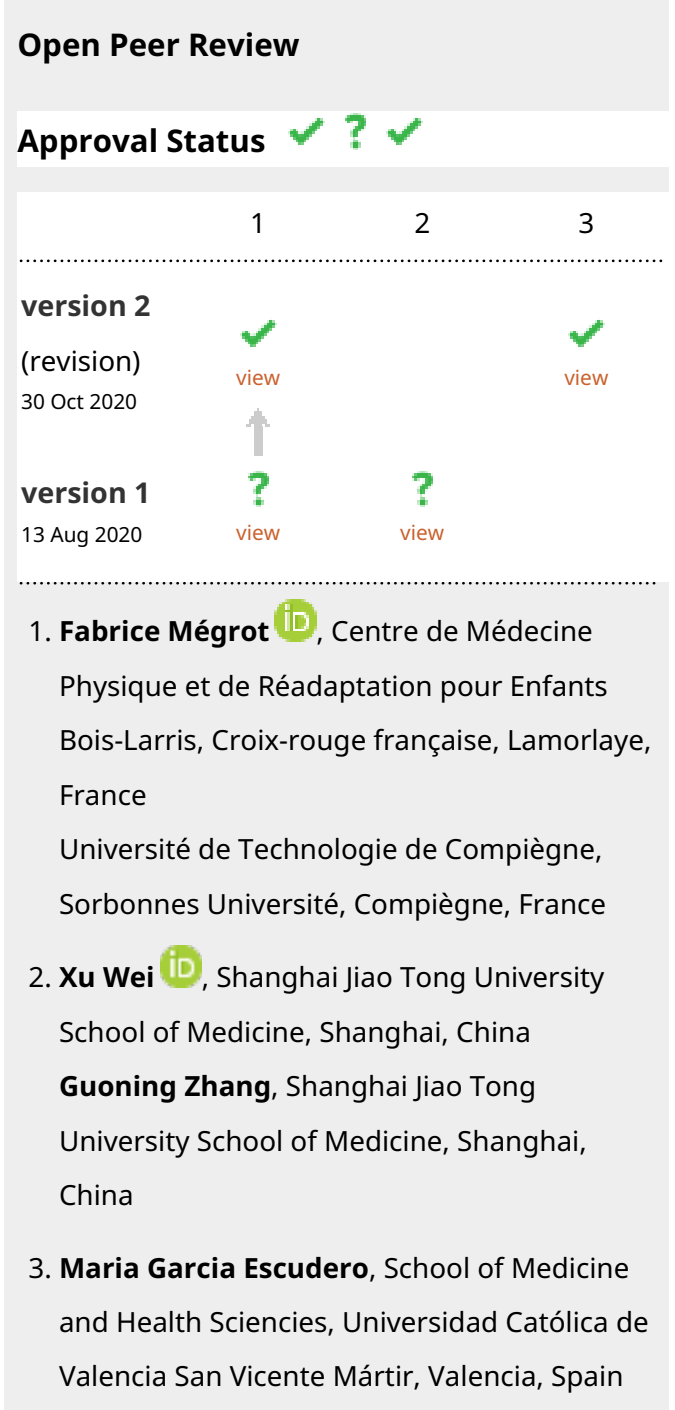


effect of using stretching to improve gait. Further randomized controlled trials are needed to understand the impact of stretching on human gait.
Any reports and responses or comments on the article can be found at the end of the article.

\section{Keywords}

stretching, gait, performance, balance, physical therapy

Corresponding author: Arnaud Delafontaine (arnaud_94150@hotmail.fr)

Author roles: Vialleron T: Conceptualization, Methodology, Writing - Original Draft Preparation; Delafontaine A: Conceptualization, Methodology, Writing - Original Draft Preparation; Ditcharles S: Writing - Review \& Editing; Fourcade P: Writing - Review \& Editing; Yiou E: Supervision, Writing - Review \& Editing

Competing interests: No competing interests were disclosed.

Grant information: The author(s) declared that no grants were involved in supporting this work.

Copyright: ( 2020 Vialleron T et al. This is an open access article distributed under the terms of the Creative Commons Attribution License, which permits unrestricted use, distribution, and reproduction in any medium, provided the original work is properly cited.

How to cite this article: Vialleron T, Delafontaine A, Ditcharles $S$ et al. Effects of stretching exercises on human gait: a systematic review and meta-analysis [version 1; peer review: 2 approved with reservations] F1000Research 2020, 9:984

https://doi.org/10.12688/f1000research.25570.1

First published: 13 Aug 2020, 9:984 https://doi.org/10.12688/f1000research.25570.1 


\section{Introduction}

Gait is a highly complex motor skill that is classically considered as an integrative measure and a predictor of health in older adults (e.g. 1; cf. also 2 and 3 for recent research topics on this matter). The loss of gait or its alteration with pathological conditions are known to be related to mortality, especially in the elderly (e.g. 4,5), stressing the importance of addressing gait disorders in physiotherapy. Gait requires body propulsion and balance control for safe progression, two "subtasks" that require the coordination of multiple skeletal muscles and the integration of sensory information arising from the vestibular, visual and somatosensory systems ${ }^{6-8}$. As such, gait may expose populations with sensory or motor deficits to the risk of falling with serious consequences for health and autonomy. For these reasons, improving gait is a major aim in rehabilitation for most neurological/orthopaedic disorders, such as stroke or Parkinson's disease, and for frail older adults. Various therapeutic methods have been used to improve gait, such as resistance training ${ }^{9}$, endurance training ${ }^{10}$, balance training ${ }^{11}$, whole body vibrations (for a complete review, see Fischer et al., 2019 ${ }^{12}$ ), multicomponent exercise programs ${ }^{13}$ and stretching ${ }^{14}$.

The successful completion of numerous daily life activities is conditioned by the ability to move efficiently through a sufficient range of motion (ROM) $)^{15}$. Recent studies on gait initiation $^{16-18}$ and seat-to-stand $\operatorname{task}^{19,20}$ showed that the experimental restriction of postural chain ROM induced by orthosis wear in young healthy adults led to instability and lower motor performance. It is well established that ROM significantly decreases with aging ${ }^{21-26}$ and more generally with reduced functional demand (e.g. sedentarity, immobilization, disease etc. $)^{15}$. Consequently, stretching has become an important part of many sport and rehabilitation programs to maintain or improve ROM, reduce stiffness and promote physical activity. This method has been applied in older adults ${ }^{27,28}$, patients with stroke ${ }^{29}$, Parkinson's disease $^{30}$, multiple sclerosis $^{31}$, plantar fasciitis ${ }^{32}$ and spastic paraplegia $^{33}$, for example. In sport programs, the influence of stretching on motor performance remains an issue of debate, although recent reviews conclude that maximal muscle performance (e.g. force, power, jump height, reaction time, etc.) is impaired primarily immediately after long durations of stretch (>90 seconds) $)^{34,35}$. To date, no review has collected results on the relationship between stretching and locomotor performance in rehabilitation programs.

Hence, the purpose of this article is to analyse the effects of a stretching program on gait in each patient category by means of a systematic literature review and meta-analysis, comparing the gait outcomes of the intervention groups with the control groups. It will contribute to provide evidence-based practice from scientific data in order to integrate stretching in rehabilitation programs in a reasoned manner.

\section{Methods}

\section{Design and literature screening}

The Preferred Reporting Items for Systematic Reviews and Meta-Analyses (PRISMA) methodology was employed in this systematic review ${ }^{36}$. A completed PRISMA checklist was submitted to an online repository (Reporting guidelines).
PubMed, Science Direct, Springer and Sage databases were used for a comprehensive systematic literature search for articles published prior to 28 April 2020 with no time limit. In addition, a manual search was conducted using the reference list of selected studies. The keywords used for the search strategy in PubMed were: "stretching" AND (gait OR walk). We included only articles published in English or French.

The selection procedure was conducted by two experts in rehabilitation (TV and AD). Disagreements were discussed with a third expert in a group until a mutual consensus was reached. First, a review was performed on all available titles obtained from the literature search with the selected keywords. All relevant or potentially relevant titles were included in the subsequent phase. Then, the abstracts were reviewed with all relevant or potential articles included in the following phase. Finally, full-text articles were reviewed to ensure that only relevant studies were included. In the same way, reference lists of all included articles were reviewed to possibly include articles through cross-referencing.

\section{Inclusion and exclusion criteria}

We included randomized controlled trials (RCT) and controlled clinical trials (CCT) published in peer-reviewed journals that aimed to explore the effects of stretching on gait parameters. We included all categories of subjects, all stretching techniques and different durations of treatment since standardized protocols are lacking in the purpose of the present study. Gait could be evaluated by functional tests, electromyographic (EMG) or biomechanical analysis. The following exclusion criteria were used: lack of gait assessment, non-application of muscle stretching, multimodal exercise programs, no control group, case report and review.

\section{Data extraction and main measurements examined}

Data were extracted from the selected articles by one of the authors (TV). The extracted data were checked by another author (AD) and disagreements were resolved with a third (EY).

The following data were extracted for each selected article: (1) the names of the authors and the date of publication; (2) the number of subjects involved in the experiment with their characteristics and breakdown in each group; (3) stretching training details (in the following order: number of participants, stretching technique, muscle groups stretched, number of sets, duration of stretch, frequency, protocol duration); (4) control group details; and (5) the main outcomes related to gait with the main results. When information could not be provided, it was indicated by a "?".

\section{Quality and risk of bias assessment}

The PEDro scale was used to assess the risk of bias, and thus the methodological quality of the selected studies ${ }^{37}$. This scale was chosen for its ability to provide an overview of the external (criterion 1), internal (criteria 2-9) and statistical (criteria 9 and 10) validity of clinical trials. The scale is divided into 11 criteria, but the first is not calculated in the total score. The output of each criterion could be either "yes" (y), "no" (n) or "do not know" (?). A "y" was given a score of one point, while 
an " $n$ " or "?" was assigned zero points. Studies with a total score of $5-10 / 10(\geq 50 \%)$ were considered to be of high quality, and scores of $0-4 / 10(<50 \%)$ of low quality ${ }^{38}$. Two evaluators independently assessed the quality of the included studies. In the event of disagreement, a group discussion was held with a third expert to reach a consensus.

\section{Statistical analysis}

Estimates of effect sizes (comparing the intervention group and the control group) accompanied with a measure of statistical uncertainty (95\% confidence interval [95\% CI]) were calculated for each outcome when sufficient data were reported. Estimates of effect sizes were reported by standard mean difference (SMD) and their respective $95 \%$ CI. In this way, the magnitude of the overall effect can be quantified as trivial $(<0.2)$, small $(0.2-0.49)$, moderate $(0.5-0.79)$ or large $(\geq 0.8)^{39,40}$. When data were lacking to calculate estimates of effect sizes, exact $\mathrm{p}$ values were reported.

When at least two studies used the same outcome, meta-analysis was performed, comparing the intervention groups with the control groups. When outcomes were identified in only one study, no meta-analysis could be performed but the effect of intervention was still calculated, reporting the estimate of effect size and its 95\% confidence interval. Statistical analysis and figures (i.e. forest plot to facilitate the visualization of values) were produced using a random-effect model in Review Manager software (RevMan, v 5.3, Cochrane Collaboration, Oxford UK). A random-effect model was used to take into account heterogeneity between study effects. Statistical heterogeneity was calculated using the $\mathrm{I}^{2}$ and Cochrane $\mathrm{Q}$ statistic tests ${ }^{39}$. Statistical significance was set at $\mathrm{p}<0.05$.

\section{Level of evidence}

The strength of evidence of primary outcomes was established as described by Van Tulder et al. $2003^{41}$ based on effect size estimates with a measure of statistical uncertainty (SMD; 95\% CI), statistical heterogeneity $\left(\mathrm{I}^{2}\right)$ when applicable (multiple studies) and risk of bias (PEDro scale). The level of evidence was considered strong with consistent findings among multiple high-quality RCT (at least two RCT with a PEDro score $\geq 5 / 10$ that were statistically homogenous: $\mathrm{I}^{2} \mathrm{p} \geq 0.05$ ). The level of evidence was considered moderate with consistent findings among multiple low-quality RCT and/or CCT (two trials with a PEDro score $<5 / 10$ that were statistically homogenous) and/or one high quality RCT. The level of evidence was considered limited when only one low quality RCT and/or CCT was identified. The level of evidence was conflicting when there was inconsistency among multiple trials $\left(\mathrm{I}^{2} \mathrm{p}<0.05\right)$.

\section{Results}

\section{Included studies}

A total of 821 titles were screened in the first search stage, one more was included through cross-referencing, and 671 were excluded because they did not concern our research question. Following exclusion, 150 studies were considered for an abstract review. A further 105 were excluded in this second stage because they did not meet the inclusion criteria. Finally, 45 full-text articles were assessed for eligibility with 33 not accepted (Figure 1).

Thus, 12 articles were ultimately included in this systematic review. Six studies evaluated the effects of stretching in healthy older adults ${ }^{14,42-46}$, one in a frail elderly population ${ }^{47}$, one study in an elderly population with stable symptomatic peripheral artery disease ${ }^{48}$, one in stroke patients ${ }^{49}$, one study in adults with limited ankle ROM associated with a history of lower limb overuses injury ${ }^{50}$, one study in healthy adults with limited ankle dorsiflexion range of motion ${ }^{51}$ and one in healthy young adults $^{52}$. A summary of the studies selected is provided in Table 1, and their quality assessment is reported in Table 2. The results in different patient categories are reported below.

\section{Results in different patient categories \\ Healthy older adults \\ Description of the studies and quality assessment}

Six studies examined the effects of stretching on healthy elderly subjects ${ }^{14,42-46}$. Regarding the characteristics of the subjects, the average sample size was $46.6 \pm 33.9$ subjects (ranging from $19^{14}$ to 96 subjects $^{44}$ ) and the mean age was $70.1 \pm 3.6$ years (ranging from $65.40^{43}$ to 75.30 years ${ }^{14}$ ). Regarding the characteristics of the training programs, the average training duration was $8.6 \pm 2.7$ weeks (ranging from $4^{43}$ to 12 weeks ${ }^{45}$ ), with an average frequency of $8.3 \pm 6.2$ sessions per week (ranging from $2^{45}$ to 14 sessions $^{42,44,46}$ ). The average number of sets per session was $4.5 \pm 2.8$ sets (ranging from $2^{46}$ to 10 sets $^{14}$ ), with an average stretching time of $45.0 \pm 18.9$ seconds (ranging from $15^{14}$ to 60 seconds $\mathrm{s}^{43,45,46}$ ). Static stretching was provided in all studies. The muscle groups stretched were the hip flexors ${ }^{42-44,46}$, ankle plantar flexors ${ }^{14,42,43,45}$, ankle dorsiflexors ${ }^{45}$, hip extensors ${ }^{43}$, knee extensors and flexors ${ }^{45}$. There was great heterogeneity in gait outcomes. Angular variables during gait included peak hip extension $^{42,44,46}$, ankle plantar flexion during gait ${ }^{44}$, ankle range of motion during gait ${ }^{43}$, anterior pelvis tilt ${ }^{43,46}$, knee range of motion $^{43}$, pelvic rotation ${ }^{43}$, lateral pelvic tilt ${ }^{43}$ and hip range of motion $^{43}$. Spatiotemporal variables were: gait speed $^{42,43,46}$, stance and swing durations ${ }^{43}$, double support phases $^{43}$, step length ${ }^{43}$ and stride length ${ }^{43,46}$. Kinetic variables were hip torque ${ }^{44}$ and ankle plantar flexion power ${ }^{44}$. Finally, two functional tests were used: the 10 -meter walk test $(10 \mathrm{MWT})^{14}$ and the 6-minute walk test $(6 \mathrm{MWT})^{45}$. Regarding the quality of the studies, the average PEDro score was $4.6 \pm 1.6$ and one study was identified as a non-randomized trial ${ }^{45}$. The range of score varied from $3^{45,46}$ to $7^{14}$.

\section{Meta-analyses}

Four meta-analysis were conducted for the following outcomes (Figure 2): gait speed, stride length, hip extension during gait and anterior pelvic tilt.

Gait speed: For gait speed (Figure 2A), two studies were included in the meta-analysis ${ }^{42,43}$. One study was excluded because intervention and control groups were not similar at baseline ${ }^{46}$. Statistical analysis showed no significant difference between 


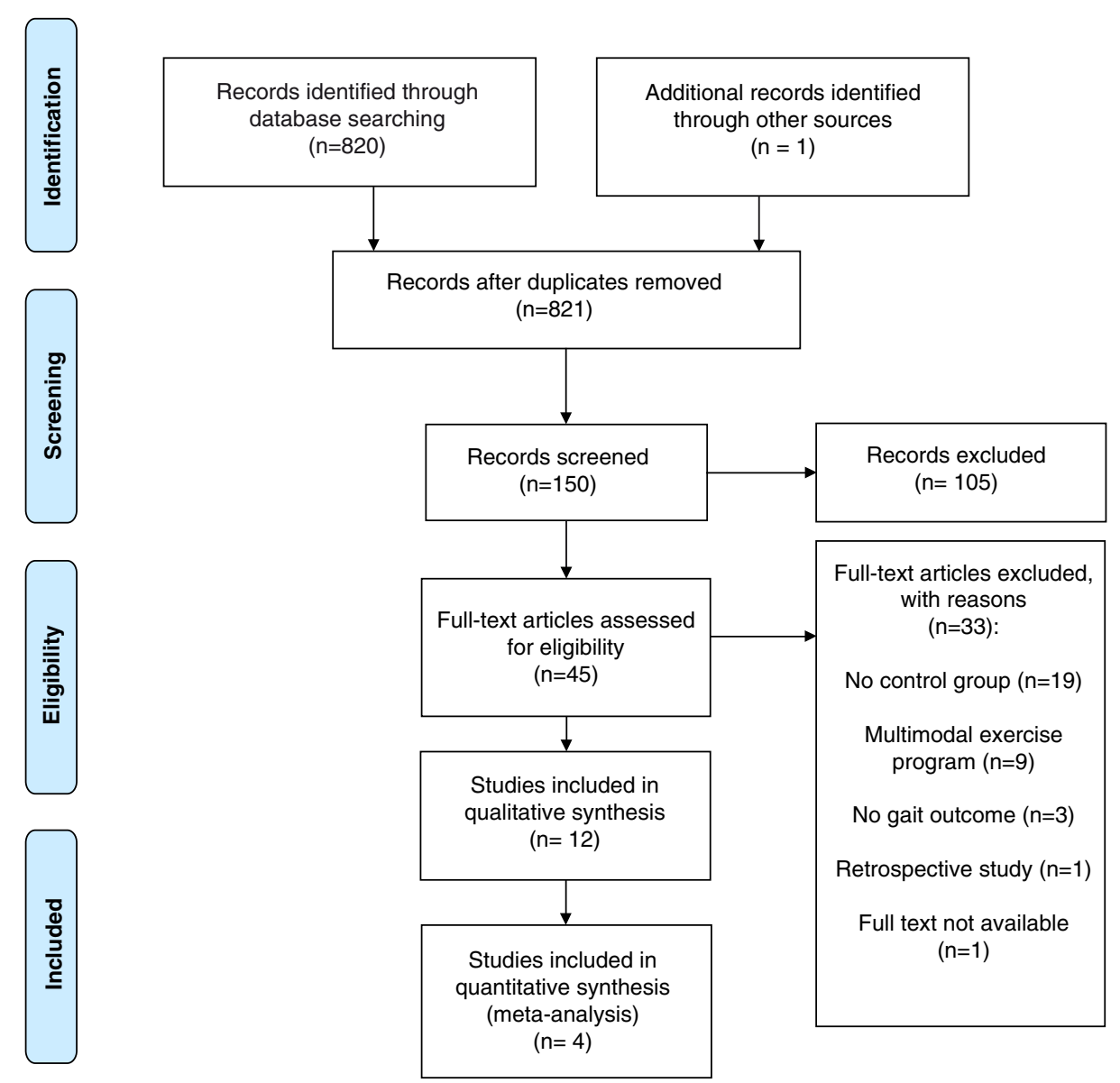

Figure 1. PRISMA flow chart of study selection process.

groups $(\mathrm{SMD}=0.45 ; 95 \% \mathrm{CI}:-1.15,2.06)$, with heterogeneous results $\left(I^{2}=86 \%, p=0.007\right)$. Thus, the level of evidence was conflicting.

Stride length: For stride length (Figure 2B), two studies were included in the meta-analysis ${ }^{42,46}$. Statistical analysis showed no significant difference between groups $(\mathrm{SMD}=0.22$; 95\% CI: $-0.44,0.88)$, with consistent results $\left(I^{2}=59 \%, p=0.12\right)$. Only one study was of high quality ${ }^{42}$, thus a moderate level of evidence supports the lack of beneficial effect of stretching to improve stride length in the elderly.

Hip extension: For hip extension during gait (kinematic data) (Figure 2C), three studies were included in the meta-analysis ${ }^{42,44,46}$. Statistical analysis showed no significant difference between groups $(\mathrm{SMD}=0.20 ; 95 \% \mathrm{CI}:-0.06,0.47)$, with consistent results $\left(\mathrm{I}^{2}=0 \%, \mathrm{p}=0.99\right)$. Two studies were of high quality ${ }^{42,44}$, thus a strong level of evidence supports the lack of beneficial effect of stretching to improve hip range of motion during gait in the elderly.

Anterior pelvic tilt: For anterior pelvic tilt (Figure 2D), three studies were included in the meta-analysis ${ }^{42,44,46}$. Statistical analysis showed no significant difference between groups
$(\mathrm{SMD}=-0.70 ; 95 \% \quad \mathrm{CI}:-1.60,0.21)$, with heterogeneous results $\left(\mathrm{I}^{2}=87 \%, \mathrm{p}<0.01\right)$. Thus, the level of evidence was conflicting.

\section{Effects of interventions in other outcomes}

For the outcomes below, no meta-analysis could be performed because only one study was identified. Nevertheless, for each outcome, effect size estimates with a measure of statistical uncertainty $(95 \% \mathrm{CI})$ were provided.

Angular variables during gait initiation: The study of Christiansen et al. (2008) ${ }^{42}$ showed no significant difference between stretching and control groups for ankle dorsiflexion during gait (SMD $=0.29$; 95\% CI: $-0.36,0.94)$ with a moderate level of confidence (PEDro score: 5/10). The study of Kerrigan et al. $(2003)^{44}$ showed no significant difference between groups for ankle plantar flexion (SMD $=-0.05$; 95\% CI: -0.45 , 0.35 ), with a moderate level of confidence (PEDro score: 6/10). The study of Cristopoliski et al. (2009) $)^{43}$ showed no significant difference between groups for lateral pelvic tilt $(\mathrm{SMD}=0.93$; 95\% CI: $-0.02,1.88)$ and knee range of motion $(\mathrm{SMD}=0.23$; $95 \%$ CI: $-0.67,1.12$ ), with a moderate level of confidence (PEDro score: 6/10). 


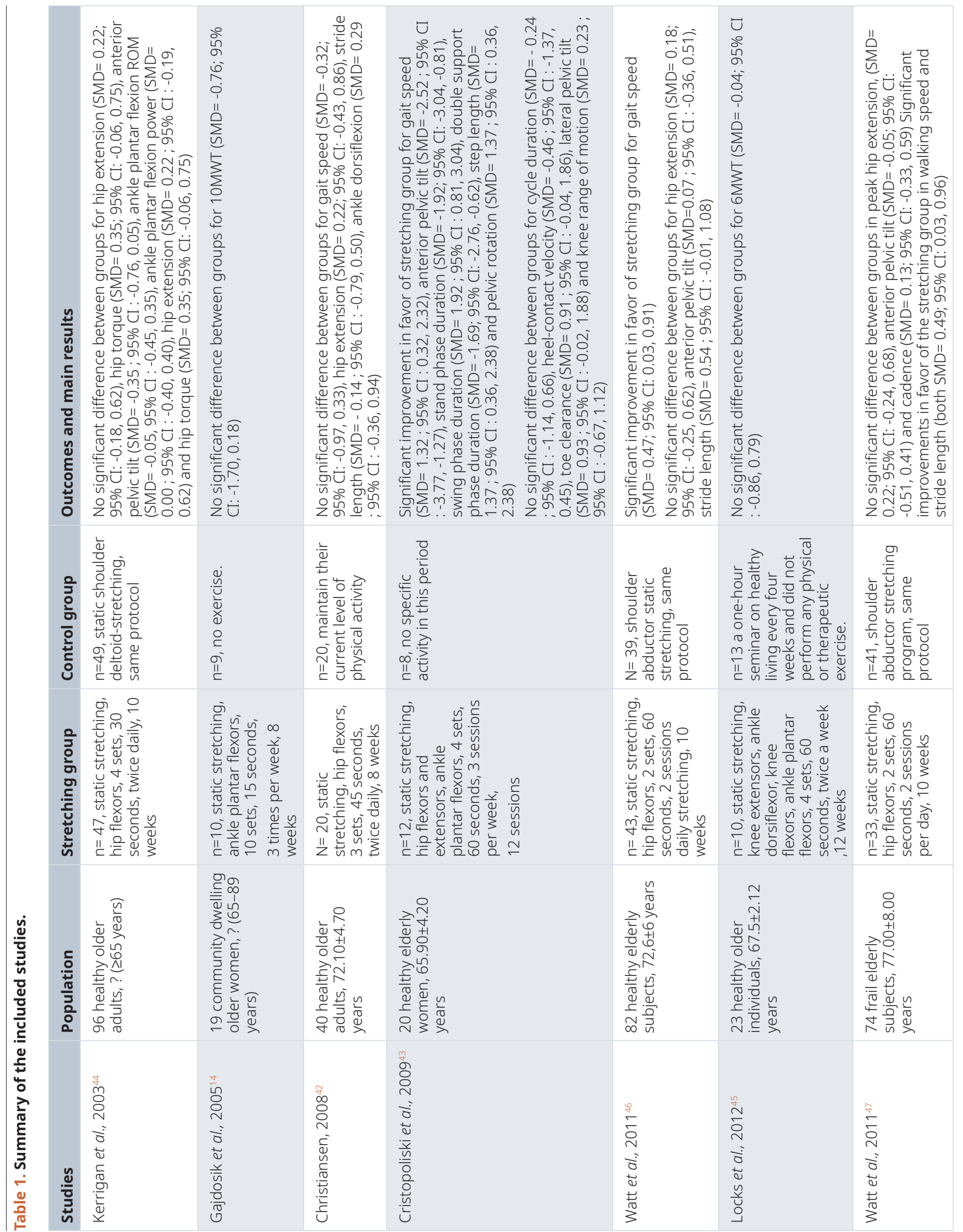




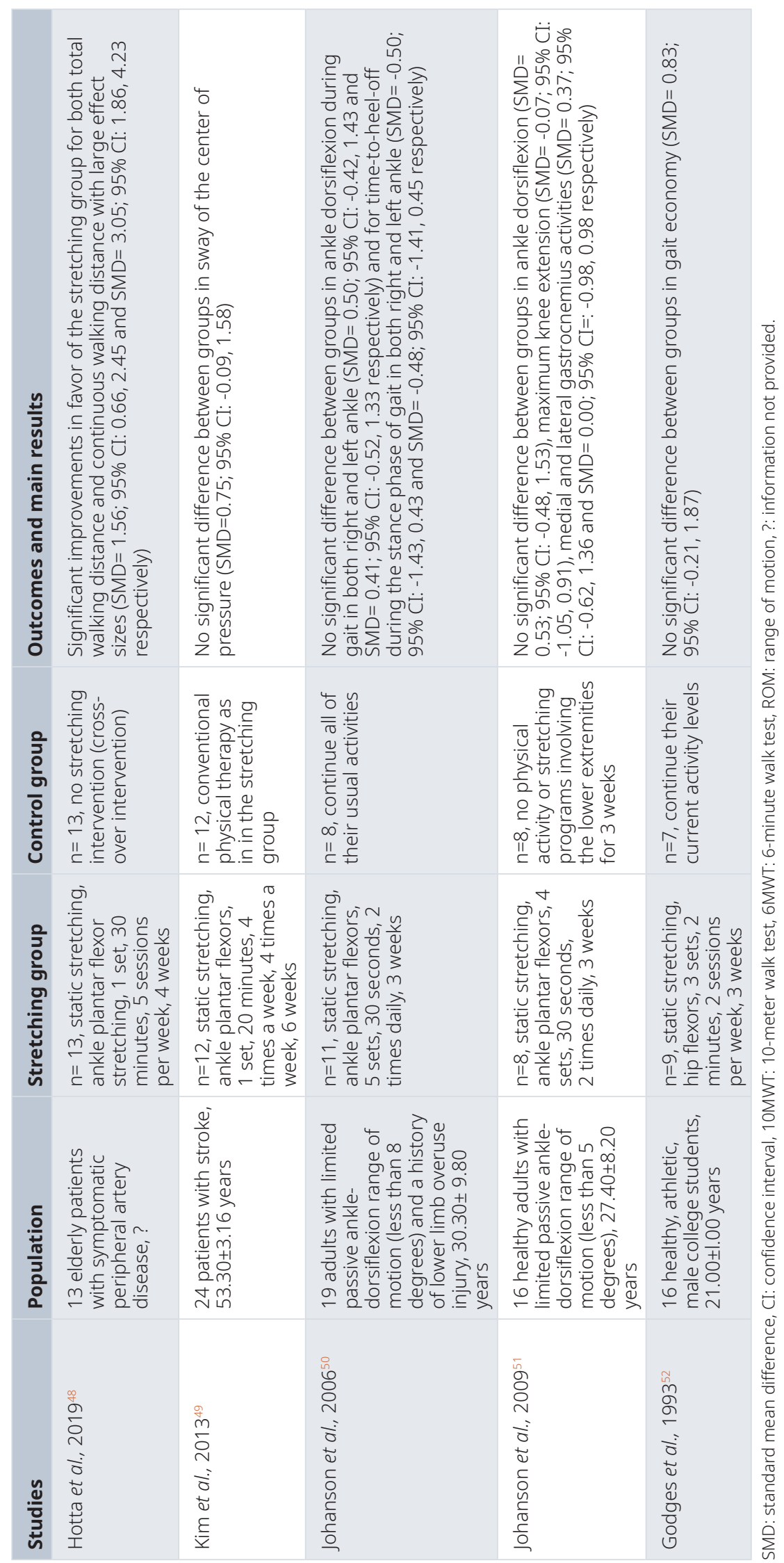




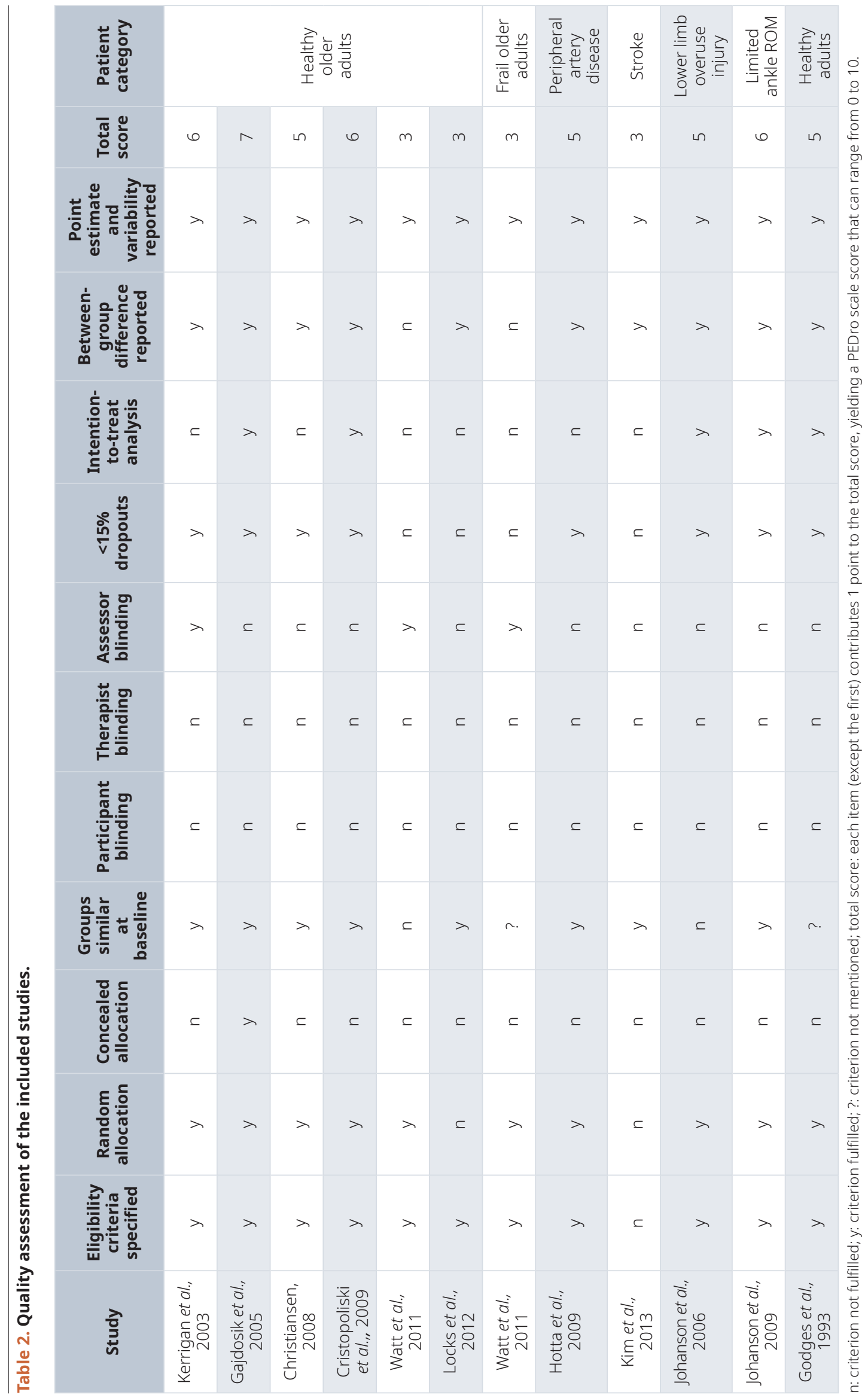


A

\begin{tabular}{|c|c|c|c|c|c|c|c|c|c|c|c|}
\hline \multirow[b]{2}{*}{ Study or Subgroup } & \multicolumn{3}{|c|}{ Intervention } & \multicolumn{3}{|c|}{ Control } & \multicolumn{2}{|r|}{ Std. Mean Difference } & \multirow{2}{*}{\multicolumn{2}{|c|}{$\begin{array}{l}\text { Std. Mean Difference } \\
\text { IV, Random, } 95 \% \mathrm{CI}\end{array}$}} & \\
\hline & Mean & SD & Total & Mean & SD & Total & Weight & IV, Random, $95 \% \mathrm{CI}$ & & & \\
\hline Christiansen 2008 & 1.3 & 0.1 & 18 & 1.35 & 0.19 & 19 & $52.8 \%$ & $-0.32[-0.97,0.33]$ & & -담- & \\
\hline Cristopoliski 2009 & 1.22 & 0.13 & 12 & 1.06 & 0.09 & 8 & $47.2 \%$ & $1.32[0.32,2.32]$ & & & \\
\hline Total $(95 \% \mathrm{Cl})$ & & & 30 & & & 27 & $100.0 \%$ & $0.45[-1.15,2.06]$ & & & \\
\hline \multicolumn{8}{|c|}{$\begin{array}{l}\text { Heterogeneity: } \mathrm{Tau}^{2}=1.16 ; \mathrm{Chi}^{2}=7.22, \mathrm{df}=1(\mathrm{P}=0.007) ; \mathrm{I}^{2}=86 \% \\
\text { Test for overall effect: } \mathrm{Z}=0.55(\mathrm{P}=0.58)\end{array}$} & & $!_{-4}$ & $\begin{array}{ll}-1 & -2 \\
\text { Favours Control Favo }\end{array}$ & 4 \\
\hline
\end{tabular}

B

\begin{tabular}{|c|c|c|c|c|c|c|c|c|c|c|}
\hline \multirow[b]{2}{*}{ Study or Subgroup } & \multicolumn{3}{|c|}{ Intervention } & \multicolumn{3}{|c|}{ Control } & \multicolumn{2}{|r|}{ Std. Mean Difference } & \multirow{2}{*}{$\begin{array}{l}\text { Std. Mean Difference } \\
\text { IV, Random, } 95 \% \mathrm{CI}\end{array}$} & \\
\hline & Mean & SD & Total & Mean & SD & Total & Weight & IV, Random, 95\% CI & & \\
\hline Christiansen 2008 & 1.36 & 0.15 & 18 & 1.39 & 0.25 & 19 & $46.7 \%$ & $-0.14[-0.79,0.50]$ & & \\
\hline Watt 2011 & 1.44 & 0.19 & 43 & 1.34 & 0.17 & 19 & $53.3 \%$ & $0.54[-0.01,1.08]$ & . & \\
\hline Total $(95 \% \mathrm{Cl})$ & & & 61 & & & 38 & $100.0 \%$ & $0.22[-0.44,0.88]$ & & \\
\hline $\begin{array}{l}\text { Heterogeneity: } \mathrm{Tau}^{2} \\
\text { Test for overall effec }\end{array}$ & $\begin{array}{l}0.14 ; C \\
Z=0.6\end{array}$ & $\begin{array}{l}C^{2} i^{2}= \\
65(P=\end{array}$ & $\begin{array}{l}2.46, \mathrm{c} \\
=0.52)\end{array}$ & $f=1$ & 0.1 & 12); $1^{2}=$ & $=59 \%$ & & $\begin{array}{cc}1 & 1 \\
-2 & 0 \\
\text { Favours Control Favours Int }\end{array}$ & $\begin{array}{l}1 \\
\text { tervention }\end{array}$ \\
\hline
\end{tabular}

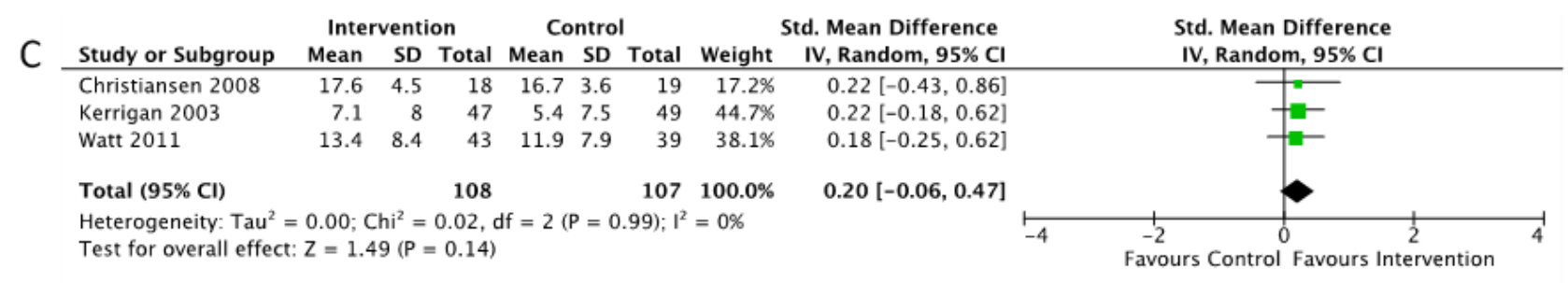

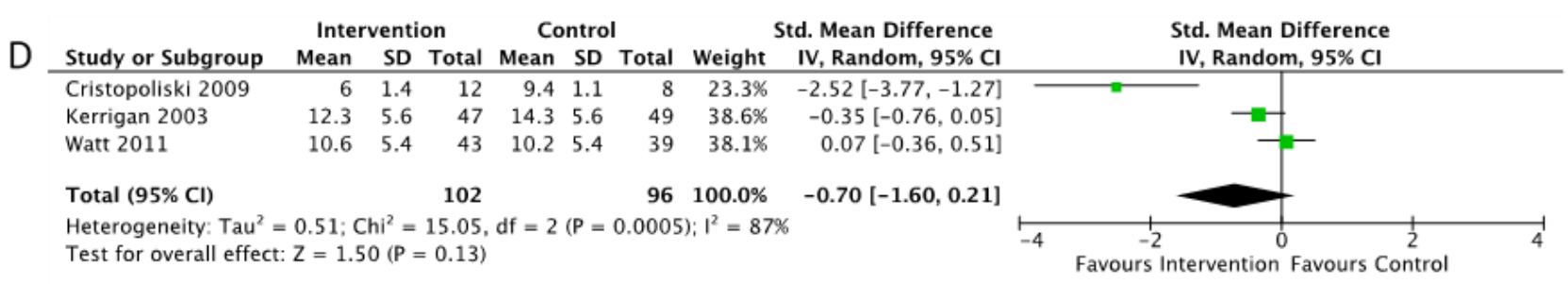

Figure 2. Comparisons between intervention and control groups for gait speed (A), stride length $(\mathbf{B})$, hip extension $(\mathbf{C})$ and anterior pelvic tilt (D) in healthy older adults.

Kinetic variables: The study of Kerrigan et al. (2003) ${ }^{44}$ showed no significant difference between groups for hip torque $(\mathrm{SMD}=0.35 ; 95 \% \mathrm{CI}:-0.06,0.75)$ and ankle plantar flexion power $(\mathrm{SMD}=0.00 ; 95 \% \mathrm{CI}:-0.40,0.40)$, with a moderate level of confidence (PEDro score: 6/10).

Spatiotemporal variables: The study of Cristopoliski et al. $(2009)^{43}$ showed no significant difference between groups for cycle duration $(\mathrm{SMD}=-0.24 ; 95 \% \mathrm{CI}:-1.14,0.66)$, heel contact velocity $(\mathrm{SMD}=-0.46 ; 95 \% \mathrm{CI}:-1.37,0.45)$ and toe clearance $(\mathrm{SMD}=0.91 ; 95 \% \mathrm{CI}:-0.04,1.86)$. However, the study showed significant decreases with large effect sizes in stance phase duration (SMD=-1.92; 95\% CI: $-3.04,-0.81)$, double support phase duration $(\mathrm{SMD}=-1.69 ; 95 \% \mathrm{CI}:-2.76,-0.62)$ in favour of the stretching group as compared to the control group. Additionally, the authors found significant increases with large effect sizes of swing phase duration ( $\mathrm{SMD}=1.92 ; 95$ CI: $0.81,3.04)$ and step length $(\mathrm{SMD}=1.37 ; 95 \% \mathrm{CI}: 0.36,2.38)$ in favour of the stretching group as compared to the control group. The study obtained a PEDro score of 6/10, thus, the level of evidence for these outcomes was moderate.

Functional tests: The study of Gajdosik et al. (2005) ${ }^{14}$ showed no significant difference between groups for the 10MWT $(\mathrm{SMD}=-0.76 ; 95 \% \mathrm{CI}=-1.70,0.18)$, with a moderate level of confidence (PEDro score: 7/10). The study of Locks et al. $(2012)^{45}$ showed no significant improvement of the 6MWT in favour of the stretching group as compared to the control group $(\mathrm{SMD}=-0.04 ; 95 \%$ CI:-0.86, 0.79) with a limited level of confidence (low quality CCT with a PEDro score of 3/10).

\section{Frail elderly}

Description of the study and quality assessment

The study of Watt et al. 2011 examined the effects of stretching on frail elderly subjects ${ }^{47}$. Regarding the characteristics of the subjects, 74 subjects were included, and the mean age 
was $77.0 \pm 8.0$ years. Regarding the characteristics of the training programs, the stretching program lasted ten weeks, with a frequency of 14 sessions per week (two sessions per day). Participants performed two sets per session, holding the stretch for 60 seconds (static stretching), alternating the right and left limb (four minutes in total). The muscle group stretched was the hip flexors. The outcomes were cadence (steps/minute), walking speed (meters/second), stride length (meters) peak hip extension (degree) and peak anterior pelvic tilt (degree). Regarding the quality assessment, the study was identified as RCT and had an average PEDro score of 3 (low level of evidence).

\section{Effects of intervention}

The study of Watt et al. (2011) showed no significant difference between groups in angular variables, i.e. peak hip extension and anterior pelvic tilt $(\mathrm{SMD}=0.22 ; 95 \% \mathrm{CI}:-0.24,0.68$ and $\mathrm{SMD}=-0.05 ; 95 \% \mathrm{CI}:-0.51,0.41$ respectively). There was also no significant difference for cadence $(\mathrm{SMD}=0.13$; 95\% CI: $-0.33,0.59)$. However, the study showed significant improvements in favour of the stretching group with small effect sizes in some performance-related variables, i.e. walking speed and stride length (both $\mathrm{SMD}=0.49 ; 95 \% \mathrm{CI}$ : $0.03,0.96$ ).

\section{Elderly with symptomatic peripheral artery disease}

Description of the study and quality assessment

The study of Hotta et al. (2019) examined the effects of stretching in elderly with symptomatic peripheral artery disease ${ }^{48}$. Regarding the characteristics of the subjects, 13 subjects were included and the mean age was not mentioned. Regarding the characteristics of the training programs, the stretching program lasted four weeks, with a frequency of five sessions per week. Participants performed one set daily, holding the stretch for 30 minutes (static stretching with splints). The muscle group stretched was ankle plantar flexors. The gait outcome was 6MWT. Regarding the quality assessment, the study was identified as RCT and had an average PEDro score of 5 (moderate level of evidence).

\section{Effects of intervention}

The study of Hotta et al. (2019) showed significant improvements in favour of the stretching group for both total walking distance and continuous walking distance with large effect sizes $(\mathrm{SMD}=1.56 ; 95 \% \mathrm{CI}: 0.66,2.45$ and $\mathrm{SMD}=3.05 ; 95 \% \mathrm{CI}: 1.86$, 4.23 respectively).

\section{Stroke}

\section{Description of the study and quality assessment}

The study of Kim et al. (2013) examined the effects of stretching on stroke patients ${ }^{49}$. Only a static muscle stretching training group and control group were included in the analysis. Regarding the characteristics of the subjects, 24 subjects were included, and the mean age was $53.3 \pm 3.1$ years. Regarding the characteristics of the training programs, the stretching program lasted six weeks, with a frequency of four sessions per week. Participants performed one set per session, holding the stretch for 20 minutes (static stretching). The muscle group stretched was ankle plantar flexors. The outcome was the sway of the centre of pressure during the stance phase.
Regarding the quality assessment, the study was identified as CCT and had an average PEDro score of 3 (low level of evidence).

\section{Effects of intervention}

The study of Kim et al. (2013) showed no significant difference between groups in the sway of the centre of pressure $(\mathrm{SMD}=0.75 ; 95 \% \mathrm{CI}:-0.09,1.58)$.

\section{Young adults with limited ankle range of motion and a history of lower limb overuse injury \\ Description of the study and quality assessment}

The study of Johanson et al. (2006) examined the effects of stretching on healthy adults with limited passive ankledorsiflexion range of motion (less than eight degrees) and a history of lower limb overuse injury ${ }^{50}$. Regarding the characteristics of the subjects, 19 subjects were included and the mean age was $30.3 \pm 9.8$ years. Regarding the characteristics of the training programs, the stretching program lasted three weeks, with a frequency of two sessions per day. Participants performed five sets per session, holding the stretch for 30 seconds (static stretching). The muscle group stretched was ankle plantar flexors. The outcomes were ankle dorsiflexion and time-to-heel-off during the stance phase of gait. Regarding the quality assessment, the study was identified as RCT and had an average PEDro score of 5 (moderate level of evidence).

\section{Effects of intervention}

The study of Johanson et al. (2006) showed no significant difference between groups in ankle dorsiflexion during gait in both the right and left ankle (SMD $=0.50 ; 95 \%$ CI: $-0.42,1.43$ and $\mathrm{SMD}=0.41 ; 95 \% \mathrm{CI}:-0.52,1.33$ respectively). There was also no significant difference between groups for time-to-heel-off during the stance phase of gait in both the right and left ankle $(\mathrm{SMD}=-0.50 ; 95 \% \mathrm{CI}:-1.43,0.43$ and $\mathrm{SMD}=-0.48 ; 95 \%$ CI: $-1.41,0.45$ respectively).

\section{Young adults with limited ankle range of motion Description of the study and quality assessment}

The study of Johanson et al. (2009) examined the effects of stretching on young adults with limited passive ankledorsiflexion range of motion (less than five degrees) ${ }^{51}$. Regarding the characteristics of the subjects, 16 subjects were included, and the mean age was $27.4 \pm 8.2$ years. The characteristics of the training programs were the same as described above $^{50}$. The muscle group stretched was the ankle plantar flexors. The outcomes were maximum ankle dorsiflexion, maximum knee extension and EMG amplitude of the gastrocnemius during the stance phase of gait. Regarding the quality assessment, the study was identified as RCT and had an average PEDro score of 6 (moderate level of evidence).

\section{Effects of intervention}

The study of Johanson et al. (2009) showed no significant difference between groups in angular variables during gait, i.e. maximum ankle dorsiflexion and maximum knee extension $(\mathrm{SMD}=0.53 ; 95 \% \mathrm{CI}:-0.48,1.53$ and $\mathrm{SMD}=-0.07 ; 95 \%$ CI: $-1.05,0.91$ respectively). There was also no significant 
difference between groups for EMG variables, i.e. medial and lateral gastrocnemius activity $(\mathrm{SMD}=0.37 ; 95 \% \mathrm{CI}:-0.62,1.36$ and $\mathrm{SMD}=0.00 ; 95 \% \mathrm{CI}=:-0.98,0.98$ respectively).

\section{Healthy young adults}

Description of the study and quality assessment

The study of Godges et al. (1993) examined the effects of stretching on healthy young adults ${ }^{52}$. Only a static hip extension stretching group and control group were included in the analysis. Regarding the characteristics of the subjects, 16 subjects were included, and the mean age was $21.0 \pm 1.0$ years. Regarding the characteristics of the training programs, the stretching program lasted three weeks, with a frequency of two sessions per week. Participants performed three sets per session, holding the stretch for two minutes (static stretching). The muscle group stretched was the hip flexors. The outcome was walking economy $(\mathrm{ml} / \mathrm{kg} / \mathrm{min})$. Regarding the quality assessment, the study was identified as RCT and had an average PEDro score of 5 (moderate level of evidence).

\section{Effects of intervention}

The study of Godges et al. (1993) showed no significant difference between groups in gait economy in terms of oxygen consumption $(\mathrm{SMD}=0.83$; $95 \% \mathrm{CI}:-0.21,1.87)$.

\section{Discussion}

The aim of this systematic review was to determine the effects of a stretching program on human gait by means of a systematic literature review and meta-analysis. Twelves studies were identified in six different patient categories. Statistical analyses showed no strong level of evidence supporting the beneficial effect of a stretching program to improve any gait outcome. The major issue in conducting meta-analyses and establishing strong level of evidences was the great heterogeneity in gait variables. The results obtained in the different patient categories are discussed in detail below.

\section{Healthy older adults}

The healthy older adult population was the most studied. Two muscle groups were systematically stretched in the six identified studies: hip flexors ${ }^{42-44,46,47}$ and ankle plantar flexors ${ }^{14,42,43}$. Hip flexor stiffness, associated with reduced hip extension during gait has been demonstrated in the elderly and may alter gait ${ }^{53,54}$. In the same way, decreased calf muscle length associated with restricted dorsiflexion range of motion is well documented in older adults ${ }^{26,55,56}$. A decreased ankle dorsiflexion ROM has been correlated with poorer balance test scores in the elderly ${ }^{57}$ and may contribute to an increased risk of falls ${ }^{58}$. All the studies included in the present analysis showed that specific stretching programs were efficient to improve passive range of motion of the targeted joints, but results are more heterogeneous regarding gait performance and dynamic ROM. This led to inconsistency in the results or the impossibility to conclude with a strong level of evidence that a stretching program improves gait in healthy older adults. Moreover, when improvement in ROM or gait performance occurred, it was not associated with a significant increase in dynamic hip extension or ankle dorsiflexion. Only trends toward increased dynamic ROM after stretching interventions were observed ${ }^{42,44,46}$. This observation was consistent in young adults.

\section{Stroke patients}

In stroke patients, ankle plantar flexor stretching has been successfully used to improve ankle stiffness ${ }^{59-62}$. Decreased plantar flexors stiffness may have a beneficial effect on postural control during gait because triceps surae is known to play an important role during gait ${ }^{63-65}$ and an increase in muscle stiffness might alter synergistic muscle activities during human gait. However, only one non-randomized study ${ }^{49}$ was identified and included in the current systematic review. Other studies that used stretching in multicomponent programs ${ }^{66-68}$ or in control groups ${ }^{69,70}$ were identified but excluded because of the addition of resistance training or the lack of a control group. Nevertheless, it should be noted that some studies showed improvements between pre- and post-stretching conditions. Forrester et al. (2014) showed that both robotic ankle mobilizations and manual ankle stretching improved gait velocity in stroke patients at hospital discharge compared to baseline $^{69}$. Similarly, Park et al. (2018) showed that both static ankle stretching and ankle mobilizations improved gait speed after four weeks of treatment compared to baseline ${ }^{70}$. Other authors showed that one week of immobilization in dorsiflexed position (casting) followed by one week of plantar flexor stretching and gait training improved gait performances in $10 \mathrm{MWT}$ and $6 \mathrm{MWT}^{66}$. Hence, these encouraging results suggest that further randomized controlled trials of good quality are needed to explore the ability of ankle stretching to improve gait parameters in stroke or in other neurological diseases exposing patients to joint stiffness, e.g. Parkinson's disease $^{71}$.

\section{Young adults}

In healthy adults, the interest of practicing stretching to improve gait seems limited as they are assumed to have sufficient mobility for walking. Moreover, the included study involved athletic males ${ }^{52}$, a population that is known to be more flexible than inactive persons ${ }^{72}$. Even in young adults with limited ankle ROM, stretching did not improve dynamic dorsiflexion during gait $^{50,51}$. Stretching programs in apparently healthy adults should be more indicated after a prolonged period of reduced functional demand (e.g. immobilization, sedentarity), when ROM is insufficient to practice a specific activity or when high levels of flexibility are required for sport performance (e.g. gymnastics or dance) and in sports that involve stretch-shortening cycles (e.g. basketball, volleyball) ${ }^{15}$.

\section{Conclusion}

Twelve studies were identified, involving a total of 442 subjects. Despite some improvements in isolated studies, statistical analyses showed no strong level of evidence supporting the beneficial effect of using stretching alone to improve gait outcomes in rehabilitation programs. The major obstacle in conducting meta-analyses and establishing strong levels of evidence were the great heterogeneity in gait variables and the low quality of the included studies. Because the effects of stretching are not clear, further randomized controlled trials of good 
quality are needed to understand the impact of stretching on human gait. Currently, stretching is more recommended to maintain and improve ROM rather than improve gait parameters and should be integrated in multicomponent programs.

\section{Data availability}

Underlying data

All data underlying the results are available as part of the article and no additional source data are required.

\section{Reporting guidelines}

Harvard Dataverse: PRISMA checklist and PRISMA flow diagram for 'Effects of stretching exercises on human gait: a systematic review and meta-analysis', https://doi.org/10.7910/ DVN/N8ZXNB ${ }^{73}$.

Data are available under the terms of the Creative Commons Zero "No rights reserved" data waiver (CCO 1.0 Public domain dedication).
1. LeBrasseur NK: Gait as an Integrative Measure and Predictor of Health Across Species. J Gerontol A Biol Sci Med Sci. 2019; 74(9): 1411-1412. PubMed Abstract | Publisher Full Text

2. Blumen HM, Cavallari P, Mourey F, et al.: Editorial: Adaptive Gait and Postural Control: from Physiological to Pathological Mechanisms, Towards Prevention and Rehabilitation. Front Aging Neurosci. 2020; 12: 45. PubMed Abstract | Publisher Full Text | Free Full Text

3. Yiou E, Hamaoui A, Allali G: Editorial: The Contribution of Postural Adjustments to Body Balance and Motor Performance. Front Hum Neurosci. 2018; 12: 487

PubMed Abstract | Publisher Full Text | Free Full Text

4. White DK, Neogi T, Nevitt MC, et al.: Trajectories of Gait Speed Predict Mortality in Well-Functioning Older Adults: The Health, Aging and Body Composition Study. J Gerontol A Biol Sci Med Sci. 2013; 68(4): 456-464. PubMed Abstract | Publisher Full Text | Free Full Text

5. Rodríguez-Molinero A, Herrero-Larrea A, Miñarro A, et al: The spatial parameters of gait and their association with falls, functional decline and death in older adults: a prospective study. Sci Rep. 2019; 9(1): 8813. PubMed Abstract | Publisher Full Text | Free Full Text

6. Allum JH, Bloem BR, Carpenter MG, et al.: Proprioceptive control of posture: a review of new concepts. Gait Posture. 1998; 8(3): 214-242. PubMed Abstract | Publisher Full Text

7. Horak FB: Postural orientation and equilibrium: what do we need to know about neural control of balance to prevent falls? Age Ageing. 2006; 35 Suppl 2: ii7-ii11.

PubMed Abstract | Publisher Full Text

8. Mirelman A, Shema S, Maidan I, et al.: Gait. Handb Clin Neurol. 2018; 159 119-134.

PubMed Abstract | Publisher Full Text

9. Arcolin I, Pisano F, Delconte C, et al.: Intensive cycle ergometer training improves gait speed and endurance in patients with Parkinson's disease: A comparison with treadmill training. Restor Neurol Neurosci. 2015; 34(1): 125-138.

PubMed Abstract | Publisher Full Text

10. Lustosa LP, Silva JP, Coelho FM, et al.: Impact of resistance exercise program on functional capacity and muscular strength of knee extensor in pre-frail community-dwelling older women: a randomized crossover trial. Rev Bras Fisioter. 2011; 15(4): 318-324. PubMed Abstract | Publisher Full Text

11. Halvarsson A, Franzén E, Ståhle A: Balance training with multi-task exercises improves fall-related self-efficacy, gait, balance performance and physical function in older adults with osteoporosis: a randomized controlled trial. Clin Rehabil. 2015; 29(4): 365-375. PubMed Abstract | Publisher Full Text

12. Fischer M, Vialleron T, Laffaye G, et al.: Long-Term Effects of Whole-Body Vibration on Human Gait: A Systematic Review and Meta-Analysis. Front Neurol. 2019; 10: 627.

PubMed Abstract | Publisher Full Text | Free Full Text

13. Freiberger $E$, Häberle L, Spirduso WW, et al.: Long-term effects of three multicomponent exercise interventions on physical performance and fall-related psychological outcomes in community-dwelling older adults: a randomized controlled trial. J Am Geriatr Soc. 2012· 60(3): 437-446. PubMed Abstract | Publisher Full Text

14. Gajdosik RL, Vander Linden DW, McNair PJ, et al.: Effects of an eight-week stretching program on the passive-elastic properties and function of the calf muscles of older women. Clin Biomech (Bristol, Avon). 2005; 20(9): 973-983. PubMed Abstract | Publisher Full Text

15. Portero $P, M c N a i r P$ : Les étirements musculo-tendineux : des données scientifiques à une pratique raisonnée. Kinésithérapie, la Revue. 2015;
15(164-165): 32-40.

Publisher Full Text

16. Delafontaine A, Gagey O, Colnaghi S, et al.: Rigid Ankle Foot Orthosis Deteriorates Mediolateral Balance Control and Vertical Braking during Gait Initiation. Front Hum Neurosci. 2017; 11: 214. PubMed Abstract | Publisher Full Text | Free Full Text

17. Delafontaine A, Fourcade $P$, Honeine JL, et al: Postural adaptations to unilateral knee joint hypomobility induced by orthosis wear during gait initiation. Sci Rep. 2018; 8(1): 830

PubMed Abstract | Publisher Full Text | Free Full Text

18. Delafontaine A, Honeine JL, Do MC, et al: Comparative gait initiation kinematics between simulated unilateral and bilateral ankle hypomobility: Does bilateral constraint improve speed performance? Neurosci Lett. 2015; 603: 55-59.

PubMed Abstract | Publisher Full Text

19. Hamaoui A, Alamini-Rodrigues C: Influence of Cervical Spine Mobility on the Focal and Postural Components of the Sit-to-Stand Task. Front Hum Neurosci. 2017; 11: 129.

PubMed Abstract | Publisher Full Text | Free Full Text

20. Alamini-Rodrigues C, Hamaoui A: Effect of three different lumbar splints on posturokinetic capacity when performing the sit-to-stand task. Ann Phys Rehabil Med. 2017; 60(6): 406-409. PubMed Abstract | Publisher Full Text

21. Grimston SK, Nigg BM, Hanley DA, et al.: Differences in ankle joint complex range of motion as a function of age. Foot Ankle. 1993; 14(4): 215-222. PubMed Abstract | Publisher Full Text

22. James B, Parker AW: Active and passive mobility of lower limb joints in elderly men and women. Am J Phys Med Rehabil. 1989; 68(4): 162-167. PubMed Abstract | Publisher Full Text

23. McKay MJ, Baldwin JN, Ferreira P, et al.: Normative reference values for strength and flexibility of 1,000 children and adults. Neurology. 2017; 88(1): 36-43.

PubMed Abstract | Publisher Full Text | Free Full Text

24. Roach KE, Miles TP: Normal hip and knee active range of motion: the relationship to age. Phys Ther. 1991; 71(9): 656-665. PubMed Abstract | Publisher Full Text

25. Soucie JM, Wang C, Forsyth A, et al.: Range of motion measurements: reference values and a database for comparison studies. Haemophilia. 2011; 17(3): 500-507. PubMed Abstract | Publisher Full Text

26. Vandervoort AA, Chesworth BM, Cunningham DA, et al.: Age and sex effects on mobility of the human ankle. J Gerontol. 1992; 47(1): M17-21. PubMed Abstract | Publisher Full Text

27. Lee PG, Jackson EA, Richardson CR: Exercise Prescriptions in Older Adults. Am Fam Physician. 2017; 95(7): 425-432. PubMed Abstract

28. Mora JC, Valencia WM: Exercise and Older Adults. Clin Geriatr Med. 2018; 34(1): $145-162$

PubMed Abstract | Publisher Full Text

29. Beyaert C, Vasa R, Frykberg GE: Gait post-stroke: Pathophysiology and rehabilitation strategies. Neurophysiol Clin. 2015; 45(4-5): 335-355. PubMed Abstract | Publisher Full Text

30. Abbruzzese G, Marchese R, Avanzino L, et al.: Rehabilitation for Parkinson's disease: Current outlook and future challenges. Parkinsonism Relat Disord. 2016; 22 Suppl 1: S60-S64. PubMed Abstract | Publisher Full Text

31. Bisht B, Darling WG, White EC, et al.: Effects of a multimodal intervention on gait and balance of subjects with progressive multiple sclerosis: a 
prospective longitudinal pilot study. Degener Neurol Neuromuscul Dis. 2017; 7: 79-93.

PubMed Abstract | Publisher Full Text | Free Full Text

32. Thong-On S, Bovonsunthonchai $S$, Vachalathiti R, et al.: Effects of Strengthening and Stretching Exercises on the Temporospatial Gait Parameters in Patients With Plantar Fasciitis: A Randomized Controlled Trial. Ann Rehabil Med. 2019; 43(6): 662-676. PubMed Abstract | Publisher Full Text | Free Full Text

33. van Lith $\mathrm{BJH}$, den Boer J, van de Warrenburg BPC, et al.: Functional effects of botulinum toxin type $A$ in the hip adductors and subsequent stretching in patients with hereditary spastic paraplegia. J Rehabil Med. 2019; 51(6): 434-441.

PubMed Abstract | Publisher Full Text

34. Behm DG, Chaouachi A: A review of the acute effects of static and dynamic stretching on performance. Eur J Appl Physiol. 2011; 111(11): 2633-2651. PubMed Abstract | Publisher Full Text

35. Kay AD, Blazevich AJ: Effect of acute static stretch on maximal muscle performance: a systematic review. Med Sci Sports Exerc. 2012; 44(1): 154-164. PubMed Abstract | Publisher Full Text

36. Moher D, Liberati A, Tetzlaff J, et al.: Preferred Reporting Items for Systematic Reviews and Meta-Analyses: The PRISMA Statement. PLoS Med. 2009; 6(7): e1000097.

PubMed Abstract | Publisher Full Text | Free Full Text

37. de Morton NA: The PEDro scale is a valid measure of the methodological quality of clinical trials: a demographic study. Aust J Physiother. 2009; 55(2): 129-133.

PubMed Abstract | Publisher Full Text

38. Lindberg J, Carlsson J: The effects of whole-body vibration training on gait and walking ability - A systematic review comparing two quality indexes. Physiother Theory Pract. 2012; 28(7): 485-98.

PubMed Abstract | Publisher Full Text

39. Higgins J, Green S: Cochrane Handbook for Systematic Reviews of Interventions Version 5.1.0 [Updated March 2011]. The Cochrane Collaboration, 2011.

Reference Source

40. Cohen J: Statistical Power Analysis for the Behavioral Sciences. 2nd ed. L. Erlbaum Associates; 1988.

Publisher Full Text

41. van Tulder M, Furlan A, Bombardier C, et al.: Updated Method Guidelines for Systematic Reviews in the Cochrane Collaboration Back Review Group. Spine (Phila Pa 1976). 2003; 28(12): 1290-1299.

PubMed Abstract | Publisher Full Text

42. Christiansen $\mathrm{CL}$ : The effects of hip and ankle stretching on gait function of older people. Arch Phys Med Rehabil. 2008; 89(8): 1421-1428.

PubMed Abstract | Publisher Full Text

43. Cristopoliski F, Barela JA, Leite N, et al.: Stretching Exercise Program Improves Gait in the Elderly. Gerontology. 2009; 55(6): 614-620. PubMed Abstract | Publisher Full Text

44. Kerrigan DC, Xenopoulos-Oddsson A, Sullivan MJ, et al.: Effect of a hip flexorstretching program on gait in the elderly. Arch Phys Med Rehabil. 2003; 84(1): 1-6.

PubMed Abstract | Publisher Full Text

45. Locks RR, Costa TC, Koppe S, et al.: Effects of strength and flexibility training on functional performance of healthy older people. Rev Bras Fisioter. 2012; 16(3): 184-190.

PubMed Abstract | Publisher Full Text

46. Watt JR, Jackson K, Franz JR, et al.: Effect of a Supervised Hip Flexor Stretching Program on Gait in Elderly Individuals. PM R. 2011; 3(4): 324-329. PubMed Abstract | Publisher Full Text

47. Watt JR, Jackson K, Franz JR, et al.: Effect of a Supervised Hip Flexor Stretching Program on Gait in Frail Elderly Patients. PM R. 2011; 3(4): 330-335. PubMed Abstract | Publisher Full Text

48. Hotta K, Batchelor WB, Graven J, et al.: Daily Passive Muscle Stretching Improves Flow-Mediated Dilation of Popliteal Artery and 6-minute Walk Test in Elderly Patients with Stable Symptomatic Peripheral Artery Disease. Cardiovasc Revasc Med. 2019; 20(8): 642-648. PubMed Abstract | Publisher Full Text | Free Full Text

49. Kim TH, Yoon JS, Lee JH: The Effect of Ankle Joint Muscle Strengthening Training and Static Muscle Stretching Training on Stroke Patients' C.O.P Sway Amplitude. J Phys Ther Sci. 2013; 25(12): 1613-1616. PubMed Abstract | Publisher Full Text | Free Full Text

50. Johanson MA, Wooden M, Catlin PA, et al.: Effects of gastrocnemius stretching on ankle dorsiflexion and time-to heel-off during the stance phase of gait. Phys Ther Sport. 2006; 7(2): 93-100. Publisher Full Text

51. Johanson MA, Cuda BJ, Koontz JE, et al.: Effect of stretching on ankle and knee angles and gastrocnemius activity during the stance phase of gait. J Sport Rehabil. 2009; 18(4): 521-534.

PubMed Abstract | Publisher Full Text

52. Godges JJ, MacRae PG, Engelke KA: Effects of Exercise on Hip Range of Motion, Trunk Muscle Performance, and Gait Economy. Phys Ther. 1993; 73(7): 468-477.

PubMed Abstract | Publisher Full Text
53. Kerrigan DC, Lee LW, Collins J], et al.: Reduced hip extension during walking: healthy elderly and fallers versus young adults. Arch Phys Med Rehabil. 2001; 82(1): 26-30.

PubMed Abstract | Publisher Full Text

54. Kerrigan DC, Todd MK, Della Croce U, et al.: Biomechanical gait alterations independent of speed in the healthy elderly: evidence for specific limiting impairments. Arch Phys Med Rehabil. 1998; 79(3): 317-322.

PubMed Abstract | Publisher Full Text

55. Gajdosik RL, Linden VWD, Williams AK: Influence of Age on Length and Passive Elastic Stiffness Characteristics of the Calf Muscle-Tendon Unit of Women. Phys Ther. 1999; 79(9): 827-838. PubMed Abstract | Publisher Full Text

56. Gajdosik RL, Vander Linden DW, McNair PJ, et al.: Slow passive stretch and release characteristics of the calf muscles of older women with limited dorsiflexion range of motion. Clin Biomech (Bristol, Avon). 2004; 19(4): 398-406. PubMed Abstract | Publisher Full Text

57. Mecagni C, Smith JP, Roberts KE, et al.: Balance and ankle range of motion in community-dwelling women aged 64 to 87 years: a correlational study. Phys Ther. 2000; 80(10): 1004-1011.

PubMed Abstract | Publisher Full Text

58. Gehlsen GM, Whaley MH: Falls in the elderly: Part II Balance, strength, and flexibility. Arch Phys Med Rehabil. 1990; 71(10): 739-741. PubMed Abstract

59. Gao F, Ren Y, Roth EJ, et al.: Effects of repeated ankle stretching on calf muscle-tendon and ankle biomechanical properties in stroke survivors. Clin Biomech (Bristol, Avon). 2011; 26(5): 516-522.

PubMed Abstract | Publisher Full Text | Free Full Text

60. Yeh $\mathrm{CY}$, Tsai $\mathrm{KH}$, Chen Jj: Effects of prolonged muscle stretching with constant torque or constant angle on hypertonic calf muscles. Arch Phys Med Rehabil. 2005; 86(2): 235-241.

PubMed Abstract | Publisher Full Text

61. Yeh CY, Chen JJ, Tsai KH: Quantitative analysis of ankle hypertonia after prolonged stretch in subjects with stroke. J Neurosci Methods. 2004; 137(2): 305-314.

PubMed Abstract | Publisher Full Text

62. Bressel E, McNair PJ: The effect of prolonged static and cyclic stretching on ankle joint stiffness, torque relaxation, and gait in people with stroke. Phys Ther. 2002; 82(9): 880-887. PubMed Abstract | Publisher Full Text

63. Honeine $\mathrm{JL}$, Schieppati $\mathrm{M}$, Gagey $\mathrm{O}$, et al.: By counteracting gravity, triceps surae sets both kinematics and kinetics of gait. Physiol Rep. 2014; 2(2): e00229.

PubMed Abstract | Publisher Full Text | Free Full Text

64. Honeine JL, Schieppati M, Gagey O, et al.: The Functional Role of the Triceps Surae Muscle during Human Locomotion. PLoS One. 2013; 8(1): e52943. PubMed Abstract | Publisher Full Text | Free Full Text

65. Neptune RR, Kautz SA, Zajac FE: Contributions of the individual ankle plantar flexors to support, forward progression and swing initiation during walking. J Biomech. 2001; 34(11): 1387-1398. PubMed Abstract | Publisher Full Text

66. Carda S, Invernizzi M, Baricich A, et al.: Casting, taping or stretching after botulinum toxin type $A$ for spastic equinus foot: a single-blind randomized trial on adult stroke patients. Clin Rehabil. 2011; 25(12): 1119-1127. PubMed Abstract | Publisher Full Text

67. Ghasemi E, Khademi-Kalantari K, Khalkhali-Zavieh M, et al:: The effect of functional stretching exercises on functional outcomes in spastic stroke patients: A randomized controlled clinical trial. J Bodyw Mov Ther. 2018; 22(4): 1004-1012.

PubMed Abstract | Publisher Full Text

68. Moore SA, Jakovljevic DG, Ford GA, et al.: Exercise Induces Peripheral Muscle But Not Cardiac Adaptations After Stroke: A Randomized Controlled Pilot Trial. Arch Phys Med Rehabil. 2016; 97(4): 596-603. PubMed Abstract | Publisher Full Text | Free Full Text

69. Forrester LW, Roy A, Krywonis A, et al:: Modular Ankle Robotics Training in Early Sub-Acute Stroke: A Randomized Controlled Pilot Study. Neurorehabi Neural Repair. 2014; 28(7): 678-687.

PubMed Abstract | Publisher Full Text | Free Full Text

70. Park D, Lee JH, Kang TW, et al.: Four-week training involving ankle mobilization with movement versus static muscle stretching in patients with chronic stroke: a randomized controlled trial. Top Stroke Rehabil. 2019; 26(2): 81-6.

PubMed Abstract | Publisher Full Text

71. Raza C, Anjum R, Shakeel NA: Parkinson's disease: Mechanisms, translational models and management strategies. Life Sci. 2019; 226: 77-90. PubMed Abstract | Publisher Full Text

72. Haff G, Triplett NT, National Strength \& Conditioning Association (U.S.), eds. Essentials of Strength Training and Conditioning. Fourth edition. Human Kinetics; 2016. Reference Source

73. Delafontaine A: Effects of stretching exercises on human gait: $A$ systematic review and meta-analysis. Harvard Dataverse, V1. 2020. http://wwww.doi.org/10.7910/DVN/N8ZXNB 


\section{Open Peer Review}

\section{Current Peer Review Status: ? ?}

\section{Version 1}

Reviewer Report 09 October 2020

https://doi.org/10.5256/f1000research.28219.r69875

(C) 2020 Wei $X$ et al. This is an open access peer review report distributed under the terms of the Creative Commons Attribution License, which permits unrestricted use, distribution, and reproduction in any medium, provided the original work is properly cited.

\section{Xu Wei}

Department of Orthopaedic Surgery, Tongren Hospital, Shanghai Jiao Tong University School of Medicine, Shanghai, China

\section{Guoning Zhang}

Department of Orthopaedic Surgery, Tongren Hospital, Shanghai Jiao Tong University School of Medicine, Shanghai, China

1. The purpose of this article is to analyse the effects of a stretching program on gait in each patient category by means of a systematic literature review and meta-analysis, comparing the gait outcomes of the intervention groups with the control groups. This is a very interesting research direction and it has good innovation. But different ages and diseases have different gait results and different stretching training modes and intervention methods. How to eliminate the bias caused by these differences in meta-analysis and comparison?

2. Four meta-analysis were conducted for the following outcomes (Figure 2): gait speed, stride length, hip extension during gait and anterior pelvic tilt. Why choose these four dimensions? Is there any theoretical basis?

3. Kinetic variables: The study of Kerrigan et al. (2003) 44 showed no significant difference between groups for hip torque (SMD $=0.35 ; 95 \% \mathrm{CI}:-0.06,0.75)$ and ankle plantar flexion power (SMD=0.00; 95\% CI: -0.40, 0.40), with a moderate level of confidence (PEDro score: $6 / 10)$.: It seems that gait analysis cannot directly measure muscle power. sEMG can only evaluate muscle recruitment signals to evaluate muscle fiber contraction. Therefore, how is ankle flexion power measured by gait analysis?

4. Twelve studies were included in the analysis. Stretching improved gait performance as assessed by walking speed and stride length only in a study with a frail elderly population, with small effect sizes. There is no strong evidence supporting the beneficial effect of using stretching to improve gait. I think that since stretching can improve gait parameters for adults with special weakness, the effect of stretching on gait is significant, although it has 
little effect on healthy adults or young adults. Should it be explained? In general, this study made a meta-analysis on the effect of stretching on gait, which has good innovation. However, whether gait analysis has guiding significance for different groups of rehabilitation training is still controversial especially for healthy adults, so the research conclusion of this paper has practical significance in clinical guidance.

Are the rationale for, and objectives of, the Systematic Review clearly stated?

Yes

Are sufficient details of the methods and analysis provided to allow replication by others? Yes

Is the statistical analysis and its interpretation appropriate? Partly

Are the conclusions drawn adequately supported by the results presented in the review? Partly

Competing Interests: No competing interests were disclosed.

Reviewer Expertise: Sports medicine; osteoporosis; osteosarcoma; Spine surgery; Scoliosis

We confirm that we have read this submission and believe that we have an appropriate level of expertise to confirm that it is of an acceptable scientific standard, however we have significant reservations, as outlined above.

Author Response 20 Oct 2020

ARNAUD DELAFONTAINE, Univ. Paris-Sud., Université Paris-Saclay, Orsay, France

Dear Reviewer

We greatly you for scrutinizing our manuscript and for his relevant comments. We feel that the manuscript has improved.

Comment 1. Different ages and diseases have different gait results and different stretching training modes and intervention methods. How to eliminate the bias caused by these differences in meta-analysis and comparison?

Reply: We add some precisions in the discussion section (healthy older adults paragraph) to specify how we have limited the risk of bias:

Please see L353-366: When data were meta-analyzed, we ensured that the groups and the training characteristics were similar to limit the risk of bias. This explains that a limited number of studies was included in the meta-analysis. It is worth noticing that the stretching technic was the same (i.e. static stretching), but that details of interventions varied across these studies. For example, both studies selected for the meta-analysis of gait speed included hip flexors and plantar flexors stretching, but, one study included hip extensor stretching ${ }^{52}$ whereas the other did not ${ }^{51}$. This difference may partially explain the 
heterogenous results in the meta-analysis $\left(\mathrm{I}^{2}=86 \%, \mathrm{p}=0.007\right)$. In the same way, the heterogenous results observed in the meta-analysis of anterior pelvic tilt $\left(\mathrm{I}^{2}=87 \%, \mathrm{p}<0.01\right)$ may be explained by the stretching of additional muscle groups (hip extensors and plantar flexors) in the study of Cristopoliski et al. (2009) compared to the other studies (in which only hip flexors were stretched) ${ }^{53,55}$. Nevertheless, heterogeneity in the results was not systematically observed between studies that used slight different protocols, as showed by the consistent results in the meta-analyses of stride length $\left(\mathrm{I}^{2}=59 \%, \mathrm{p}=0.12\right)$ and hip extension $\left(\mathrm{I}^{2}=0 \%, \mathrm{p}=0.99\right)$. Thus, we assume that we have limited the risk of bias in the meta-analyses.

Comment 2. Four meta-analysis were conducted for the following outcomes (Figure 2): gait speed, stride length, hip extension during gait and anterior pelvic tilt. Why choose these four dimensions? Is there any theoretical basis?

Reply: Only these four outcomes fitted with the inclusion criteria for meta-analysis. Metaanalyses were performed only when more than one trial was identified for each outcome. Additionally, to reduce the risk of bias, we ensured that the groups were similar. For example, in the study of Watt et al. (2011), the intervention group had a significantly higher gait speed than the control group, so the trial was excluded of the meta-analysis.

Comment 3. Kinetic variables: The study of Kerrigan et al. (2003)44 showed no significant difference between groups for hip torque $(\mathrm{SMD}=0.35 ; 95 \% \mathrm{CI}:-0.06,0.75)$ and ankle plantar flexion power (SMD=0.00; 95\% CI: $-0.40,0.40$ ), with a moderate level of confidence (PEDro score: $6 / 10$ ).: It seems that gait analysis cannot directly measure muscle power. sEMG can only evaluate muscle recruitment signals to evaluate muscle fiber contraction. Therefore, how is ankle flexion power measured by gait analysis?

Reply: In the study of Kerrigan et al. (2003), "joint torque and power calculations were based on the mass and inertial characteristics of each lower-extremity segment, the derived linear and angular velocities and accelerations of each lower-extremity segment, and the ground reaction force and joint center position estimates. Joint torques and powers were normalized for body weight and height and were reported as external in newton meters per kilogram meters (N.m/kg.m) and watts per kilogram meters (W/kg.m), respectively". Unless special recommendation of the reviewer or the Editor, we feel it is not necessary to add how the ankle flexion power was measured in the study of Kerrigan et al. (2003).

Comment 4. I think that since stretching can improve gait parameters for adults with special weakness, the effect of stretching on gait is significant, although it has little effect on healthy adults or young adults. Should it be explained?

Reply: We add some precisions in the discussion section (young adults paragraph) to specify why stretching is less interesting to improve gait parameters in young healthy adults:

Please see L387-390: In healthy adults, the interest of practicing stretching to improve gait seems limited as they are assumed to have sufficient mobility for walking. Moreover, the included study involved athletic males ${ }^{61}$, a population that is known to be more flexible 
than inactive persons ${ }^{81}$. Stretching should be more indicated when range of motion is limited ${ }^{24}$.

Best regards

Arnaud Delafontaine

on behalf of all the authors

Competing Interests: None

Reviewer Report 14 September 2020

https://doi.org/10.5256/f1000research.28219.r69874

(C) 2020 Mégrot F. This is an open access peer review report distributed under the terms of the Creative Commons Attribution License, which permits unrestricted use, distribution, and reproduction in any medium, provided the original work is properly cited.

\section{Fabrice Mégrot}

1 Unité Clinique d'Analyse de la Marche et du Mouvement, Centre de Médecine Physique et de Réadaptation pour Enfants Bois-Larris, Croix-rouge française, Lamorlaye, France

2 BioMécanique et BioIngénierie (BMBI) - UMR 7338, Université de Technologie de Compiègne, Sorbonnes Université, Compiègne, France

Authors propose a systematic review and meta-analysis to investigate the effects of stretching programs on gait and to determine how stretching might be valuable for rehabilitation. From 150 studies identified through systematic searches and critical appraisal of the literature, 12 articles were considered by the authors.

The various demographics of the participants in the reported studies implied a mixed range of age and aetiology, even if old persons, either with an asymptomatic or a pathological health status, were the most represented individuals.

In young adults, two studies by Johanson are reported. Is it not clear if both groups of young adults with limited range of motion were identical in both studies and had the same characteristics? If yes, merging the two studies should make the deal, if not please provide specification about the second group.

Overall, the methodology is correct, and the meta-analysis well described. The results show weak effects of stretching on gait parameters.

The main issue arises from the various parameters which are considered in all the studies, both during gait initiation and straight walking (spatiotemporal parameters, kinematics, joint strength and dynamics, muscle activity, etc...). Therefore, in the results and the discussion, grouping the types of parameters according to their role in the process of walking would add value to this manuscript. The effects, demonstrated or not, have not all the same meaning depending on 
whether functional parameters or kinematics angles or even muscle strength and activity are considered.

Gait should be defined in a better way, especially how it is related to the different measures in terms of processes, even if there is anyway no real benefit demonstrated by stretching used as a unique therapy. Surprisingly, no article in children with cerebral palsy has been uncovered, while the clinical care of these children is mostly based on muscle stretching.

Are the rationale for, and objectives of, the Systematic Review clearly stated?

Yes

Are sufficient details of the methods and analysis provided to allow replication by others? Yes

Is the statistical analysis and its interpretation appropriate?

Yes

Are the conclusions drawn adequately supported by the results presented in the review? Partly

Competing Interests: No competing interests were disclosed.

Reviewer Expertise: motor control, biomechanics, neurosciences, nonlinear dynamics, clinical gait/movement analysis and gross motor function of children with cerebral palsy

I confirm that I have read this submission and believe that I have an appropriate level of expertise to confirm that it is of an acceptable scientific standard, however I have significant reservations, as outlined above.

Author Response 20 Oct 2020

ARNAUD DELAFONTAINE, Univ. Paris-Sud., Université Paris-Saclay, Orsay, France

Reviewer 1 :

Dear Reviewer

We greatly you for scrutinizing our manuscript and for his relevant comments. We feel that the manuscript has improved.

Comment 1. In young adults, two studies by Johanson are reported. Is it not clear if both groups of young adults with limited range of motion were identical in both studies and had the same characteristics? If yes, merging the two studies should make the deal, if not please provide specification about the second group.The participants in both studies were different. In the study of Johanson et al. (2006), the participants were healthy adults with limited passive ankle-dorsiflexion range of motion (less than 8 degrees) and a history of lower limb overuse injury. In the study Johanson et al. (2009), the characteristics of the stretching program were the same as in Joahnson et al. (2006), but the participants did not 
have any history of lower limb overuse injury.

Reply: To make this difference clearer, precisions were added in the "included studies" and "results" sections:

Please see L158-163 Thus, 12 articles were ultimately included in this systematic review. Six studies evaluated the effects of stretching in healthy older adults 23,51-55, one in a frail elderly population 56 , one study in an elderly population with stable symptomatic peripheral artery disease ${ }^{57}$, one in stroke patients 58 , one study in adults with limited ankle range of motion (less than 8 degrees) associated with a history of lower limb overuse injury 59 , one study in healthy adults with limited ankle dorsiflexion range of motion (less than 5 degrees) 60 and one in healthy young adults 61

Please see L285-288: “The study of Johanson et al. (2006) examined the effects of stretching on healthy adults with limited passive ankle-dorsiflexion range of motion (less than 8 degrees) and a history of lower limb overuse injury ${ }^{50}$. Regarding the characteristics of the subjects, 19 subjects were included and the mean age was $30.3 \pm 9.8$ years."

Please see L302-306: "The study of Johanson et al. (2009) examined the effects of stretching on young adults with limited passive ankle-dorsiflexion range of motion (less than 5 degrees) ${ }^{51}$. It is worth noticed that these participants were not the same than in the study of Johanson et al. (2006). In contrast, the characteristics of the training programs were the same as in Johanson et al. (2006)".

Comment 2. In the results and the discussion, grouping the types of parameters according to their role in the process of walking would add value to this manuscript. The effects, demonstrated or not, have not all the same meaning depending on whether functional parameters or kinematics angles or even muscle strength and activity are considered.

Reply: In the results and the discussion, we chose to group the participants by patient categories because differences in ages and health parameters may result in different training effects. However, in each patient category, each variable was considered separately in an organized way.

Comment 3. Gait should be defined in a better way, especially how it is related to the different measures in terms of processes, even if there is anyway no real benefit demonstrated by stretching used as a unique therapy.

Reply: We agree. We add a whole paragraph at the beginning of the introduction section to specify how gait can be related to the different variables seen in the review:

Please see L35-44: "Gait is the medical term used to describe the human whole body movement of walking ${ }^{1}$. Gait involves internal and external forces that act on the body to move the center of mass (COM) across a given distance ${ }^{2}$. It depends on many biomechanical features that can be observed during gait analysis such as center of mass shifts, joint range of motion, forces, muscle activity, joint moments, and joint powers ${ }^{3}$. Spatiotemporal features (e.g. velocity, step length, stride length, step with, step variability) and kinematics parameters (range of motion) can be observed subjectively with functional 
evaluations by clinicians(e.g. the Tinetti test ${ }^{4}$ or the timed up and go test ${ }^{5}$ ), but, it can be further objectified with biomechanical analysis in a laboratory ${ }^{2}$. Kinetics variables (the forces that cause the body to move) must be collected in a laboratory environment with force plates (e.g. ${ }^{6-9}$ for recent studies that used this technic)".

Comment 4. Surprisingly, no article in children with cerebral palsy has been uncovered, while the clinical care of these children is mostly based on muscle stretching.

Reply: We agree. However, no article in children with cerebral palsy fitted our inclusion criteria during the systematic search of the literature. We add a whole paragraph in a specific section "limitations of the study":

Please see L397-406: Some patient categories were not included in the present review, although muscle stretching is commonly indicated in their clinical care to reduce spasticity 82 . This is for example the case for children with cerebral palsy ${ }^{83}$. In fact, we were able to identify studies in the literature focusing on the effects of stretching on gait in this population during the first phase of the present review, but the protocol of these studies combined stretching with another form of training (e.g. ${ }^{84,85}$ ) or there was no control group (e.g. ${ }^{86}$ ). These studies therefore did not fit with the inclusion criteria of the present systematic review and were consequently excluded. Now, it should be stressed that the effectiveness of static stretching to improve motor function in children with cerebral palsy is still controversial 87 , although some authors showed that functional stretching exercises may be effective to improve gait ${ }^{86}$. Further randomized controlled trials are needed to explore the impact of stretching on gait in this population.

Best regards

Arnaud Delafontaine

on behalf of all the authors

Competing Interests: None 
The benefits of publishing with F1000Research:

- Your article is published within days, with no editorial bias

- You can publish traditional articles, null/negative results, case reports, data notes and more

- The peer review process is transparent and collaborative

- Your article is indexed in PubMed after passing peer review

- Dedicated customer support at every stage

For pre-submission enquiries, contact research@f1000.com 